\title{
Die Trennung des Eisens \\ von Chrom, Zirkon und Beryllium durch die Einwirkung von gasförmiger Salzsäure auf die Oxyde.
}

\author{
Von \\ Franke Stuart Havens und Arthur Fitch Way. ${ }^{1}$
}

In einer kürzlich erschienenen Mitteilung ${ }^{2}$ aus diesem Laboratorium wurde nachgewiesen, dafs es möglich ist, Eisenoxyd vollständig in einem starken Salzsäurestrom bei $450-500^{\circ}$ als Chlorid zu verflüchtigen. Es hatte sich bei dieser Untersuchung gezeigt, dafs die Einwirkung auf das Eisenoxyd schon bei $180-200^{\circ}$ glatt verläuft, wenn man der Salzsäure etwas freies Chlor beimischt; man vermeidet so den Fehler, der aus der Neigung des Ferrichlorids zur Dissoziation entstehen kann, erzielt eine vollkommene Oxydation des behandelten Oxyds und hat keinen mechanischen Verlust, der aus einer zu schnellen Verflüchtigung entstehen könnte, zu befürchten. Es wurde auch nachgewiesen, dafs die geschilderte Reaktion zur Trennung von Eisen und Aluminium dienen kann, wenn man diese beiden Metalle als Oxyde verwendet; weiterhin wurde bereits darauf hingewiesen, dafs sich eventuell auch andere Metalloxyde nach dieser Methode vom Eisen trennen lassen.

Die Oxyde von Chrom, Zirkon und Beryllium werden, ebensowenig wie Aluminiumoxyd, von trockener, gasförmiger Salzsäure bei den angegebenen Temperaturen angegriffen; sie können deswegen nach dieser Methode, wie sich aus den weiterhin beschriebenen Versuchen ergiebt, vollkommen vom Eisen getrennt werden.

Die Ausführung des Verfahrens geschah stets in gleicher Weise, genau wie bei der Trennung von Eisen und Aluminium. In ein Porzellanschiffchen wurde eine gewogene Menge eines

\footnotetext{
${ }^{1}$ Ins Deutsche übertragen von J. KOPPEL.

${ }^{2}$ Gooch und Havens, Z. anorg. Chem. 21, 21.
} 
dieser Oxyde mit einer gewogenen Menge Eisenoxyd gemischt und dann in eine geräumige Glasröhre hineingebracht, welche in einem kleinen Verbrennungsofen lag. Dies Oxydgemisch behandelte man mit einem trockenen Strom chlorhaltiger Chlorwasserstoff'säure, der durch Eintropfen von Schwefelsäure in ein Gemisch starker Salzsäure mit Kochsalz und wenig Mangandioxyd hergestellt wurde. Das Gasgemisch leitete man an dem einen Ende der Verbrennungsröhre ein und liels es am anderen Ende durch einen Wasserverschlufs austreten, während gleichzeitig das Rohr durch passende Regulierung der Brenner auf einer Temperatur von $200-300^{\circ}$ gehalten wurde. Die zur Vollendung der Reaktion erforderliche Zeit variiert etwas mit der physikalischen Beschaffenheit des zu verflüchtigenden Oxyds; doch kann bei ca $200^{\circ}$ in einer Stunde etwa

\begin{tabular}{|c|c|c|c|c|}
\hline 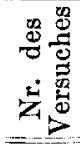 & $\begin{array}{c}\text { Angewandtes } \\
\mathrm{Fe}_{2} \mathrm{O}_{3} \\
\mathrm{~g} \\
\end{array}$ & $\begin{array}{c}\text { Angewandtes } \\
\mathrm{Cr}_{2} \mathrm{O}_{8} \\
\mathrm{~g} \\
\end{array}$ & $\begin{array}{c}\text { Gefundenes } \\
\mathrm{Cr}_{\mathbf{2}} \mathrm{O}_{\mathbf{y}} \\
\mathrm{g}\end{array}$ & $\begin{array}{c}\text { Fehler } \\
\mathrm{g}\end{array}$ \\
\hline 1 & - & 0.1008 & 0.1008 & 0.0000 \\
\hline 2 & 0.1007 & 0.1006 & 0.1006 & 0.0000 \\
\hline 3 & 0.1007 & 0.1000 & 0.1002 & +0.0002 \\
\hline 4 & 0.1010 & 0.1005 & 0.1003 & -0.0002 \\
\hline 5 & 0.1019 & 0.1006 & 0.1005 & -0.0001 \\
\hline 6 & 0.2007 & 0.1003 & 0.0999 & -0.0004 \\
\hline & & $\begin{array}{c}\mathrm{ZrO}_{2} \\
\mathrm{~g}\end{array}$ & $\begin{array}{c}\mathrm{ZrO}_{2} \\
8 \\
\end{array}$ & \\
\hline 7 & - & 0.1516 & 0.1516 & 0.0000 \\
\hline 8 & 0.1053 & 0.1010 & 0.1010 & 0.0000 \\
\hline 9 & 0.1204 & 0.1519 & 0.1523 & +0.0004 \\
\hline 10 & 0.1236 & 0.1516 & 0.1517 & +0.0001 \\
\hline 11 & 0.2150 & 0.1517 & 0.1519 & +0.0002 \\
\hline & & $\begin{array}{c}\mathrm{BeO} \\
\mathrm{g} \\
\end{array}$ & $\begin{array}{c}\mathrm{BeO} \\
\mathrm{g} \\
\end{array}$ & \\
\hline 12 & - & 0.1309 & 0.1311 & +0.0002 \\
\hline 13 & 一 & 0.1285 & 0.1285 & 0.0000 \\
\hline 14 & 0.0997 & 0.0456 & 0.0457 & +0.0001 \\
\hline 15 & 0.1045 & 0.1099 & 0.1099 & 0.0000 \\
\hline 16 & 0.1215 & 0.1080 & 0.1081 & +0.0001 \\
\hline 17 & 0.1510 & 0.1305 & 0.1290 & -0.0015 \\
\hline 18 & 0.2030 & 0.1081 . & 0.1083 & +0.0002 \\
\hline
\end{tabular}


$0.1 \mathrm{~g}$ Eisen voliständig verflüchtigt werden. Bei höheren Temperaturen geht die Reaktion schneller vor sich; man "erhält jedoch dann leicht mechanische Verluste an den anderen Oxyden, besonders an Berylliumoxyd infolge der schnellen Verdampfung des Eisenchlorids, wie deutlich aus Versuch Nr. 17, der bei $500^{\circ}$ ausgeführt wurde, hervorgeht. Es ist deshalb vorteilhafter, zunächst niedrigere Temperaturen anzuwenden und nur, wenn die Reaktion vollendet ist, die Hitze einige Minuten zu steigern, um die letzten Eisenspuren zu entfernen. Eine Prüfung zeigte, dafs die zurückbleibenden Oxyde, aus denen das Eisen nach der geschilderten Methode entfernt war, vollkommen eisenfrei sind. (Vergl. die Tabelle auf S. 390 .)

Die Trennung des Eisens von Chrom, Zirkon und Beryllium ist offenbar vollkommen und giebt sehr zufriedenstellende Resultate.

The Kent Chemieal Laboratory of Yale University, New Haven, U. S. A.

Bei der Redaktion eingegangen am 4. Juli 1899. 